\title{
Use of dietary supplements among people living with HIV/AIDS is associated with vulnerability to medical misinformation on the internet
}

\author{
Seth C Kalichman ${ }^{1 *}$, Chauncey Cherry ${ }^{1}$, Denise White ${ }^{1}$, Miche'l Jones $^{1}$, Moira O Kalichman ${ }^{1}$, Mervi A Detorio ${ }^{2}$,
} Angela M Caliendo ${ }^{2}$ and Raymond F Schinazi ${ }^{3}$

\begin{abstract}
Background: Use of dietary supplements is common among people living with HIV/AIDS. Because dietary supplements are used in the context of other health behaviors, they may have direct and indirect health benefits. However, supplements may also be associated with vulnerability to medical misinformation and unfounded health claims. We examined use of dietary supplements among people living with HIV/AIDS (PLWH) and the association between use of dietary supplements and believing medical misinformation.

Methods: A convenience sample of 268 men and 76 women living with HIV was recruited from AIDS services and clinics in Atlanta, GA. Participants completed measures of demographic and health characteristics, dietary supplement use, beliefs about dietary supplements, internet use, and an internet evaluation task designed to assess vulnerability to medical misinformation.

Results: One out of four PLWH currently used at least one dietary supplement product excluding vitamins. Dietary supplement use was associated with higher education and greater use of the internet for health-related information. Dietary supplement users also endorsed greater believability and trust in unfounded claims for HIV cures.

Conclusions: Dietary supplement use is common among PLWH and is associated with a broad array of health information seeking behaviors. Interventions are needed to reduce the vulnerability of PLWH, particularly dietary supplement users, to medical misinformation propagated on the internet.
\end{abstract}

Keywords: HIV treatment, medical misinformation, treatment beliefs, dietary supplements

\section{Introduction}

Dietary supplements play an important role in the lives of many people living with chronic and often life-threatening medical conditions. Dietary supplements generally consist of diverse products that are typically not part of current mainstream, conventional health care [1]. Concerns about dietary supplements generally stem from the potential for adverse interactions with conventional medicines and patients replacing evidence-based health care with untested remedies[2]. Studies show that dietary supplements are often used by people living with

\footnotetext{
* Correspondence: seth.k@uconn.edu

'Department of Psychology, University of Connecticut, 406 Babbidge Road, Storrs, CT 06269, USA

Full list of author information is available at the end of the article
}

HIV infection. The most common dietary supplements in people living with HIV/AIDS (PLWH) are used to 'boost immune functioning' such as mega-dose vitamins, and anti-oxidants and body cleansing products such as teas and herbs to remove 'toxins'[3]. As many as half of PLWH may use complementary and alternative medicines, which can include dietary supplements [4].

Dietary supplement users tend to engage in a range of health promoting behaviors [3,5]. Studies of cancer patients show that actively seeking health information from multiple sources is a associated with dietary supplement use [6]. It is common for PLWH who use dietary supplements to conceal these practices from their health care providers, potentially increasing the risks for interference with treatment plans[5]. PLWH who use

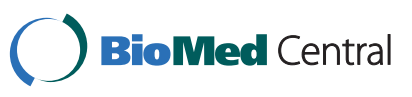


dietary supplements with the potential for adverse drug interactions are also inclined to seek health information from a variety of sources [4], including non-traditional and fringe groups, suggesting a vulnerability to misinformation and fraudulent claims.

Access to credible health information on the internet can be an important part of patient-centered health care. Unfortunately, the internet is also a major source of medical misinformation and unconventional health promotion. Incomplete and inaccurate health information is common on the internet and for many patients unreliable information sources are indistinguishable from credible ones [7-10]. Unproven cancer treatments promoted online, for example, cause significant concern and have led to measures that counter their use [11]. Similarly, South African courts have banned the promotion of vitamins to cure AIDS [12-14], after years of devastating government support for fake AIDS treatments [15-17]. Anecdote-based remedies are appealing to patients with serious health conditions because they speak in certain terms about their successes, emphasize the uncertainties and side-effects of conventional medicine, prey upon anxieties, and offer unrealistic hope [6]. Among PLWH, unsubstantiated claims by marketers of 'immune boosting products' and fake cures are often seen as credible and evoke interest in their use [9]. However, we are not aware of research that has investigated vulnerability to medical misinformation and fake claims among dietary supplement users living with HIV/ AIDS.

The purpose of the present study was to examine dietary supplement use among PLWH and its association to vulnerability to medical misinformation. First, we describe past and current use of dietary supplements in a community sample of PLWH. We then describe the demographics, health characteristics, and information seeking behaviors of current dietary supplement users compared to persons not using dietary supplements. Finally, we tested the potential vulnerability to medical misinformation among active dietary supplement users. We focused on responses to claims that HIV/AIDS can be effectively treated and cured by dietary supplements. We hypothesized that PLWH who are using dietary supplements would be more interested in and believe the claims of medical misinformation propagated on the Internet.

\section{Methods}

\section{Participants}

People living with HIV/AIDS were recruited through targeted community sampling to participate in a crosssectional study. We used both targeted venue recruitment and snowball sampling techniques to identify individuals in and out of care. Recruitment relied on responses to brochures placed in waiting rooms of HIV service providers and infectious disease clinics throughout Atlanta, GA. We also implemented an explicit systematic approach to word-of-mouth chain recruitment. Specifically, participants were given brochures that describe the study opportunity with a phone number to the research offices. Participants were encouraged to use the brochures to refer their HIV-infected friends to the study. These procedures were designed to extend recruitment beyond service settings in order to achieve a broad community sample of people living with HIV/ AIDS. The entry criteria were age 18 years or older, scored at least $80 \%$ correct on a test of functional health reading literacy (TOFHLA) [18] and showed proof of their positive HIV status.

\section{Measures}

Measures were collected at the research site using an instructor guided self-administration procedure in groups of 4 to 8 persons. Participants were shown page by page how to complete the measures by using a projected facsimile, assuring that instructions for each instrument were carefully described and that participants were given privacy when responding. Data were collected between January 2008 and June 2009. Written informed consent was obtained from the participants of this study and the study was approved the university Institutional Review Board.

\section{Demographic and health characteristics}

Participants were asked their age, years of education, income, ethnicity, HIV treatment history, and employment status. HIV related symptoms were assessed using an adapted version of a previously developed measure [19], which included 14 common symptoms of HIV infection, including developing a new skin rash, recurring fever, chronic diarrhea, and persistent shortness of breath. We asked participants to provide blood specimens to test for HIV (RNA) viral load. Blood samples were provided at the project offices using standard phlebotomy and couriered to the lab for processing. Whole blood specimens in EDTA tube (Becton Dickinson) were centrifuged at $500 \mathrm{~g}$ for $10 \mathrm{~min}$ within $4 \mathrm{hrs}$ of collection. The plasma was recovered and aliquoted into 1 $\mathrm{ml}$ samples and stored at $-70^{\circ} \mathrm{C}$. Plasma viral load was determined by Roche Amplicor HIV-1 Monitor.

Participants consented to monthly unannounced telephone-based pill counts, constituting a prospective measure of adherence. Unannounced pill counts are reliable and valid in assessing HIV treatment adherence when conducted in participants' homes [20] and on the telephone [21,22]. Participants were provided with a cell phone that restricted service for project contacts and emergency use (e.g., 911). Following office-based training in the pill counting procedure, participants were 
called at unscheduled times by a phone assessor. Pill counts occurred over 21 to 35 day intervals and were conducted for each of the medications that participants were taking. Pharmacy information from pill bottles was also collected to verify the number of pills dispensed between calls. Adherence was calculated as the ratio of pills counted relative to pills prescribed, taking into account the number of pills dispensed. Two consecutive pill counts were necessary for computing adherence monitored for eight consecutive months. This study used the mean value of all available adherence data points as a stable indicator of HIV treatment adherence.

\section{Dietary Supplements}

We created an assessment of commonly used dietary forms of complementary medicine. We derived items for this measure through 3 sources. First, we selected dietary supplements described by the National Center for Complementary and Alternative Medicine. [Antioxidants, Chamomile \& other teas, Flax seed, Macrobiotics, Probiotics, Selenium, St. Johns Wort] [1] Second, we identified additional items from previous research on the frequency of dietary supplement use among PLWH [Herbs] $[4,23]$ Finally, we held informal discussions with ten people living with HIV who participated in past research regarding their experience with dietary supplements. [Amino acid therapy, Immunotherapy, Micronutrient therapy, Orange juice pills, Chinese medicine, African medicine] The final result was 14 dietary supplements. Participants were presented with the list of dietary supplement practices and instructed to mark each for whether they (a) had ever used it since testing HIV positive and (b) whether they were currently using it. We also asked participants who reported current use of dietary supplements to estimate the amount of money they spend per month on these products.

\section{Dietary Supplement Beliefs}

We assessed participants beliefs regarding the benefits of dietary products for curing HIV infection and AIDS. Participants completed 4 items regarding vitamins, traditional and herbal remedies, and immune boosters. The exact items are shown in the results section. Items were responded to as 'Agree' and 'Disagree'.

\section{Internet use for health-related information}

Participants indicated whether they had used the Internet to find health-related information, purchase health products, and shared health information they had accessed online. Participants reported the number of times they had used the Internet for these purposes in the previous month. Open responses were collected by participants writing values in blank spaces for the number of times they performed each action.

\section{Perceptions of e-health information}

We assessed perceptions of unsubstantiated claims available on the internet regarding the use of dietary practices to treat and cure AIDS. Participants completed an internet rating task adapted from previous research $[24,25]$. For this task, webpages were obtained directly from the Internet, including color, image resolution, and text size. We selected two webpages representing false claims for using micronutrients to treat and cure AIDS: (a) Rath International: "Micronutrients Help Control AIDS" http://www4.dr-rath-foundation.org/pdf-files/ ri_2006_02_en.pdf; summarizes the findings from uncontrolled studies that have been deemed unauthorized and illegal[12,13]. The specific webpage reports 'clinical proof' that micronutrients improve the health of PLWH and that antiretroviral medications are toxic and without benefit; (b) Jonathan Campbell; "A Cure for AIDS?" http://www.cqs.com/aidscure.htm endorses the use of "immune system enhancing nutrients such as vitamin C (in absolutely massive doses) and zinc". This webpage states that the pharmaceutical industry promotes "drugs such as AZT that focus on destroying HIV (meanwhile killing the patient)".

One reputable website was included as a control: Tufts School of Medicine "Choose Snacks that work for you" http://www.tufts.edu/med/nutrition-infection/hiv/ health_snacks.html; explains the nutritional value of healthy snacks and the benefits from healthy food choices.

As a check for whether participants had read the internet passages, we asked three factual true/false questions extracted from the text of each passage. Participants also indicated their perceptions of and interest in the three sources of information by rating four dimensions: "How much do you believe this information?", "How factual is the information?", "How much do you trust the information?" and "How important is this information for you?" using 10-point scales ranging from $1=$ 'Not at all' to $10=$ 'Very much'.

\section{Data analyses}

We performed descriptive analyses to examine the frequency of past and current use of 14 dietary supplements separately for men and women. We then compared current dietary supplement users $(\mathrm{N}=93)$ to PLWH who were not currently using dietary supplement $(\mathrm{N}=251)$ on demographics, health characteristics, internet use, perceptions of website information, and dietary supplement beliefs. Comparisons on continuous measures used independent groups t-tests and categorical variables were analyzed using contingency table chisquare tests. We performed a final multivariable logistic regression analysis to test the independent effects of factors related to current dietary supplement use. This multivariable model simultaneously tested non-overlapping factors from the previous analyses found significantly associated with current dietary supplement use. 
To avoid statistical redundancy we created a total index of interest and believability of the Rath and Campbell website claims regarding treating and curing AIDS. Specifically, we calculated the mean score of the four interest and believability ratings. In addition, we created a composite of the four dietary supplement beliefs by summing the endorsements, ranging from 0 endorsed to 4. From the logistic regressions we report odds ratios with $95 \%$ confidence intervals. All analyses used casewise deletion for missing values and defined statistical significance as $\mathrm{p}<.05$.

\section{Results}

A convenience sample of 268 men and 76 women was recruited from AIDS services, health care providers, social service agencies, and infectious disease clinics in Atlanta, GA. Results showed 26\% ( $\mathrm{N}=93)$ currently used at least one dietary supplement. (see Table 1) The most commonly used dietary products were antioxidants and teas. Seventy percent $(N=65)$ of dietary supplement users reported currently using two or more products. There were no statistically significant differences in dietary supplement use between genders; men used an average of $0.82(\mathrm{SD}=1.8)$ dietary supplement products compared to women who used $0.60(\mathrm{SD}=1.45)$ products, $\mathrm{t}(\mathrm{df}=342)=0.3$. Among persons who reported current use of dietary supplements, men spent an average $\$ 49.85$ and women spent $\$ 34.29$ per month on these products, a non-significant difference, $\mathrm{t}(\mathrm{df}=343)=0.5$.

\section{Demographic and health characteristics}

Results showed that dietary supplement users had significantly more years of education. (see Table 2) There were no other significant associations between demographic characteristics and supplement use. Although dietary supplement users tended to have higher medication adherence the difference was not statistically significant. There were no other significant differences between dietary supplement non-users and users on health characteristics.

\section{Internet use for health-related information}

Dietary supplement users demonstrated significantly greater use of the internet with respect to searching for medical, treatment, and health information online. (see Table 3) Dietary supplement users were also significantly more likely to purchase health-related products in general and share information obtained online with their friends. Thus, dietary supplement users indicated significantly greater internet use for locating and sharing health-related information.

\section{Vulnerability to false claims about dietary supplements} and supplement beliefs

As an internal validity check, we first analyzed responses to the factual recall questions asked for each internet passage. Overall accuracy for identifying information contained in the website passages was high, with over $80 \%$ correct responses across the three

Table 1 Current and past dietary supplement product use among 268 men and 76 women living HIV/AIDS.

\begin{tabular}{|c|c|c|c|c|c|c|c|c|}
\hline \multirow[b]{3}{*}{ Products } & \multicolumn{4}{|c|}{ Current Supplement Use } & \multicolumn{4}{|c|}{ Past Supplement Use } \\
\hline & \multicolumn{2}{|l|}{ Men } & \multicolumn{2}{|l|}{ Women } & \multicolumn{2}{|c|}{ Men } & \multicolumn{2}{|c|}{ Women } \\
\hline & $\mathbf{N}$ & $\%$ & $\mathbf{N}$ & $\%$ & $\mathbf{N}$ & $\%$ & $\mathbf{N}$ & $\%$ \\
\hline Antioxidants & 48 & 18 & 12 & 16 & 37 & 14 & 8 & 11 \\
\hline Amino acid therapy & 8 & 3 & 0 & 0 & 15 & 6 & 2 & 3 \\
\hline Chamomile \& other teas & 48 & 18 & 10 & 13 & 27 & 11 & 6 & 8 \\
\hline Flax seed & 18 & 8 & 5 & 6 & 20 & 8 & 1 & 1 \\
\hline Herbs & 40 & 15 & 8 & 11 & 39 & 15 & 6 & 8 \\
\hline Immunotherapy & 7 & 2 & 2 & 2 & 16 & 6 & 3 & 4 \\
\hline Macrobiotics & 4 & 2 & 0 & 0 & 5 & 2 & 0 & 0 \\
\hline Micronutrient therapy & 9 & 3 & 2 & 2 & 8 & 3 & 0 & 0 \\
\hline Orange juice pills & 9 & 3 & 1 & 1 & 12 & 5 & 1 & 1 \\
\hline Probiotics & 3 & 1 & 2 & 2 & 7 & 3 & 2 & 2 \\
\hline Selenium & 12 & 5 & 4 & 5 & 18 & 7 & 1 & 1 \\
\hline St. Johns Wort & 3 & 1 & 0 & 0 & 13 & 5 & 1 & 1 \\
\hline Chinese medicine & 5 & 2 & 0 & 0 & 9 & 3 & 2 & 2 \\
\hline African medicine & 4 & 2 & 0 & 0 & 3 & 1 & 2 & 2 \\
\hline \multicolumn{9}{|c|}{ Number of products in current use } \\
\hline None & 190 & 71 & 61 & 80 & & & & \\
\hline 1 & 25 & 9 & 3 & 4 & & & & \\
\hline $2-3$ & 29 & 11 & 6 & 8 & & & & \\
\hline $4+$ & 24 & 9 & 6 & 8 & & & & \\
\hline
\end{tabular}


Table 2 Demographic and health characteristics of people living with HIV/AIDS who do not use and use dietary supplements.

\begin{tabular}{|c|c|c|c|c|c|c|}
\hline \multirow[b]{2}{*}{ Characteristic } & \multicolumn{2}{|c|}{$\begin{array}{l}\text { Do Not Use Supplements } \\
(\mathrm{n}=251)\end{array}$} & \multicolumn{2}{|c|}{ Uses Supplements $(n=93)$} & \multirow[b]{2}{*}{$\mathrm{t}$} & \multirow[b]{2}{*}{$\mathrm{p}$} \\
\hline & M & SD & M & SD & & \\
\hline Age (years) & 44.5 & 7.4 & 44.0 & 8.7 & 0.5 & n.s \\
\hline Education (years) & 12.3 & 1.9 & 13.4 & 1.9 & 4.7 & .01 \\
\hline Monthly income (\$) & 1104 & 3301 & 1029 & 1322 & 0.2 & n.s \\
\hline Years since HIV+ & 13.0 & 7.2 & 13.8 & 7.0 & 0.9 & n.s \\
\hline CD4-cell count (cells/mm³) & 445 & 314 & 516 & 320 & 1.6 & n.s \\
\hline HIV symptom score & 3.8 & 3.6 & 4.4 & 4.0 & 1.1 & n.s \\
\hline Number of AIDS diagnoses & 1.9 & 4.8 & 1.7 & 3.5 & 0.4 & n.s \\
\hline \multirow{2}{*}{ ART adherence (\%) } & 79.5 & 22.2 & 85.0 & 16.3 & 1.6 & n.s \\
\hline & $\mathrm{N}$ & $\%$ & $\mathrm{~N}$ & $\%$ & $x^{2}$ & $p$ \\
\hline Men & 190 & 76 & 78 & 83 & & \\
\hline Women & 61 & 24 & 15 & 17 & 2.6 & n.s \\
\hline African American & 233 & 93 & 84 & 90 & & \\
\hline White & 14 & 6 & 4 & 5 & & \\
\hline Other race & 3 & 1 & 5 & 5 & 5.3 & n.s \\
\hline Viral load < 50 copies & 102 & 47 & 48 & 59 & 2.9 & n.s \\
\hline Adherence $>85 \%$ & 69 & 52 & 30 & 56 & 0.2 & n.s \\
\hline
\end{tabular}

passages. However, dietary supplement users were significantly more likely to correctly report the website content, $87.7 \%(\mathrm{SD}=13.4)$, compared to non-dietary supplement users, 78.0\% $(\mathrm{SD}=17.8), \mathrm{t}(\mathrm{df}=343)=4.9$, $\mathrm{p}<.01$.

Results for the website information ratings are shown in Table 4. Comparisons indicated that in every case, for all three internet passages, dietary supplement users were significantly more inclined to believe the information, endorse its factual basis, trust it, and endorse its personal importance. This same pattern of higher interest and believability of internet health information was observed for the two false claims about treating and curing AIDS with vitamins and micronutrients as well as the control website concerning choosing healthy snacks.
A similar pattern of results emerged for endorsing beliefs that vitamins and natural remedies can treat and cure AIDS; dietary supplement users were significantly more likely to believe vitamins, healthy foods, and traditional medicines can cure AIDS. (see Table 5) Overall, dietary supplement groups significantly differed in the total number of dietary supplement beliefs endorsed, $\mathrm{t}$ $(\mathrm{df}=343)=4.29, \mathrm{p}<.01$.

\section{Multivariable model}

Table 6 presents the results of the multiple logistic regression predicting current dietary supplement use from non-redundant participant characteristics. Results showed that being younger and better educated, having an undetectable viral load at the time of the study, and using the Internet for health information and rating

Table 3 Internet use in the previous month among people living with HIV/AIDS who do not use and do use dietary supplements.

\begin{tabular}{|c|c|c|c|c|c|c|}
\hline \multirow[b]{2}{*}{ Internet use in previous month } & \multicolumn{2}{|c|}{$\begin{array}{l}\text { Do Not Use Supplements } \\
(n=251)\end{array}$} & \multicolumn{2}{|c|}{ Uses Supplements ( $\mathrm{n}=93$ ) } & \multirow[b]{2}{*}{$x^{2}$} & \multirow[b]{2}{*}{$\mathrm{p}$} \\
\hline & $\mathbf{N}$ & $\%$ & $\mathbf{N}$ & $\%$ & & \\
\hline Any use of the Internet & 116 & 46 & 73 & 79 & 29.6 & .01 \\
\hline Searched HIV treatments & 38 & 15 & 38 & 41 & 26.6 & .01 \\
\hline Purchased health products & 7 & 3 & 9 & 10 & 7.4 & .01 \\
\hline Search medication information & 35 & 14 & 28 & 30 & 12.2 & .01 \\
\hline Search general health information & 51 & 20 & 49 & 53 & 35.2 & .01 \\
\hline $\begin{array}{l}\text { Shared information from internet } \\
\text { with friend }\end{array}$ & 62 & 24 & 46 & 50 & 19.9 & .01 \\
\hline $\begin{array}{l}\text { Friend shared information } \\
\text { from internet }\end{array}$ & 52 & 21 & 42 & 45 & 21.0 & .01 \\
\hline
\end{tabular}


Table 4 Ratings of perceived HIV treatment and cure information found on the Internet among people living with HIV/AIDS who do not use and do use dietary supplements.

\begin{tabular}{|c|c|c|c|c|c|c|}
\hline \multirow[b]{2}{*}{ Internet source and perception rating } & \multicolumn{2}{|c|}{ Do Not Use Supplements $(n=251)$} & \multicolumn{4}{|c|}{ Uses Supplements $(n=93)$} \\
\hline & M & SD & M & SD & $\mathbf{t}$ & p \\
\hline \multicolumn{7}{|c|}{ Matthias Rath - "Micronutrients Help Control AIDS" } \\
\hline Believes the information & 6.4 & 2.6 & 4.2 & 2.6 & 2.3 & .05 \\
\hline Information is factual & 6.4 & 2.7 & 7.2 & 2.3 & .05 & \\
\hline Trust the information & 6.3 & 2.7 & 7.0 & 2.8 & 1.9 & n.s. \\
\hline Information is important to me & 6.9 & 2.9 & 7.8 & 2.8 & 2.3 & .05 \\
\hline \multicolumn{7}{|l|}{ Jonathan Campbell - "A Cure for AIDS?” } \\
\hline Believes the information & 6.2 & 2.8 & 7.5 & 2.6 & 3.6 & .01 \\
\hline Information is factual & 6.1 & 2.8 & 6.8 & 2.8 & 2.2 & .05 \\
\hline Trust the information & 5.8 & 2.8 & 6.9 & 2.8 & 3.4 & .01 \\
\hline Information is important to me & 7.6 & 3.0 & 8.5 & 2.6 & 2.4 & .01 \\
\hline Mean ratings Rath and Campbell scenarios & 6.5 & 2.3 & 7.3 & 2.2 & 3.3 & .01 \\
\hline \multicolumn{7}{|c|}{ Tufts Medical School - "Choose Snacks That Work for You!” } \\
\hline Believes the information & 7.9 & 2.4 & 8.9 & 1.9 & 3.6 & .01 \\
\hline Information is factual & 7.5 & 2.6 & 8.6 & 2.1 & 3.6 & .01 \\
\hline Trust the information & 7.6 & 2.5 & 8.7 & 2.0 & 3.6 & .01 \\
\hline Information is important to me & 8.2 & 2.4 & 8.8 & 2.4 & 2.0 & .05 \\
\hline
\end{tabular}

false treatment information as more interesting and believable were independently associated with the use of dietary supplements.

\section{Discussion}

Results of the current study demonstrated that one in four participants currently used at least one dietary supplement product. The overall use of dietary supplements in this sample was similar to past research with other medical populations. For example, a study of chronic lymphocytic leukemia patients found that $44 \%$ had used dietary supplements [26]. Previous research with PLWH also demonstrated similar use, such as a study of HIV positive men that found $69 \%$ used complementary medicine products and practices, the most common of which were dietary supplements [4].

The current study found that age and years of education were the only demographic characteristics associated with dietary supplement use; individuals who used dietary supplements were younger and significantly better educated. With respect to health markers, dietary supplement users were more likely to have an undetectabale viral load. It is important to note that while some dietary supplements can adversely interact with prescriprition medications, some supplements may also have positive impacts on HIV disease processes. For exampe, recent research suggests that selenium, which was used by $5 \%$ of our sample, may have benefits in treating HIV infection [27].

In the current study there was no association between supplement use and medication adherence, suggesting that participants may consider dietary supplements as co-treatments that do not interfere with their medications. Consistent with past research, we also found that dietary supplement use was associated with an array of health-related behaviors. In this case, dietary supplement users were significantly more likely to use the Internet for health-related information seeking. In addition to actively seeking health information on the internet, dietary supplement users also demonstrated greater trust in

Table 5 Dietary supplement beliefs among people living with HIV/AIDS who do not use and do use dietary supplements.

\begin{tabular}{|c|c|c|c|c|c|c|}
\hline \multirow[b]{2}{*}{ Beliefs } & \multicolumn{2}{|c|}{$\begin{array}{l}\text { Do Not Use Supplements } \\
(n=251)\end{array}$} & \multicolumn{2}{|c|}{ Uses Supplements $(\mathrm{n}=93)$} & \multirow[b]{2}{*}{$X^{2}$} & \multirow[b]{2}{*}{$p$} \\
\hline & $\mathbf{N}$ & $\%$ & $\mathbf{N}$ & $\%$ & & \\
\hline Vitamins and healthy foods can cure AIDS. & 24 & 9 & 23 & 25 & 13.6 & .01 \\
\hline Traditional medicines can cure AIDS. & 12 & 5 & 13 & 14 & 8.7 & .01 \\
\hline Herbal and natural remedies can cure AIDS in some people. & 69 & 28 & 40 & 43 & 7.5 & .01 \\
\hline HIV is treatable using non-toxic natural immune boosters. & 100 & 40 & 47 & 51 & 3.4 & n.s. \\
\hline Overall mean (SD) items endorsed ${ }^{a}$ & 0.8 & $(0.9)$ & 1.1 & $(1.1)$ & 4.84 & .01 \\
\hline
\end{tabular}

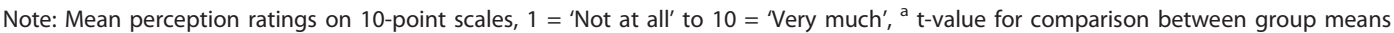


Table 6 Multiple logistic regression predicting current dietary supplement use.

\begin{tabular}{llll}
\hline Predictor & Odds Ratio & $\mathbf{p ~}$ & $\mathbf{9 5 \%} \mathbf{C l}$ \\
\hline Age & .94 & .01 & $0.91-0.98$ \\
Education & 1.47 & .01 & $1.25-1.73$ \\
Years since testing HIV positive & 1.04 & n.s. & $1.00-1.09$ \\
HIV symptoms & 1.05 & n.s. & $0.97-1.13$ \\
Undetectable viral load & 2.35 & .01 & $1.26-4.36$ \\
Searched for health information online & 1.07 & .01 & $1.01-1.13$ \\
Interest and believability of internet medical misinformation & 1.23 & .01 & $1.08-1.41$ \\
Beliefs that supplements can treat and cure AIDS & 1.41 & .05 & $1.06-1.89$ \\
\hline
\end{tabular}

internet information and more positive beliefs in the curative value of dietary supplements. In addition, dietary supplement users were more inclined to believe and trust both unfounded claims as well as credible health information. These results confirm our main study hypothesis to show that dietary supplement use is associated with accepting medical misinformation. Our cross-sectional study, however, does not allow us to infer directions of the relationships. Specifically, people who use dietary supplements may be more vulnerable to misinformation or misinformed individuals may be more prone to using dietary supplements. These results also replicate previous research that has found highrates of trust and believability in false claims on the internet among PLWH $[23,24]$. Taken together, our findings suggest that dietary supplement use may be a marker for health seeking behaviors and an openness to using diverse treatment approaches regardless of their evidence-base, suggesting a vulnerability to quackery and fraud.

The findings from this study should be interpreted in light of its methodological limitations. With the exception of viral load assessed by blood labs and medication adherence monitored using an objective assessment, our study methods relied on self-reported health status and behaviors. As noted above, our cross-sectional study design precludes any causal or directional conclusions. The content of our measures may also have influenced our findings. Specifically, our measure of dietary supplement beliefs did not necessarily include items most central to decisions about using or not using dietary supplements. Our measures also may have excluded important covariates that could help explain the results, such as illicit substance use and medication side effects. It is also unknown whether responding to the study measures inadvertently stimulated interest or reinforced interest in dietary supplements. Finally, our results are based on a convenience sample that is predominantly middle-aged, African American, and from one southern US city. In addition, our recruitment procedures may have biased the sample toward recruiting networks of people who use dietary supplements. Although our results converge with other studies, caution is warranted before generalizing these findings to other populations of PLWH.

Dietary supplements play important roles in the health practices of many PLWH. Dietary supplement use often occurs in the context of antiretroviral therapies. Patients who gravitate toward alternative treatments should be counseled on the potential for misinformation and fraud on the Internet. The value of legitimate dietary supplements can be undermined by fraudulent and confusing medical misinformation on the Internet. Patient education and counseling about dietary supplement practices should occur while respecting well-informed individual choices in health care. Interventions that teach patients health consumer and critical thinking skills have demonstrated positive outcomes, including reduced vulnerability to internet-based misinformation [10]. Wide-scale use of the internet and the proliferation of e-health products challenges providers to discuss unfounded claims as well as the relative value of dietary supplements with their patients.

\section{Acknowledgements}

This project was supported by grants from the National Institute of Mental Health (NIMH) grants R01-MH71164 (SCK), R01-MH82633 (SCK), Emory's Center for AIDS Research NIH grant 2P30-Al-050409 (RFS \& AMC) and the Department of Veterans Affairs (RFS).

\section{Author details}

${ }^{1}$ Department of Psychology, University of Connecticut, 406 Babbidge Road, Storrs, CT 06269, USA. ²Department of Pathology and Laboratory Medicine and Center for AIDS Research, Emory University School of Medicine, Medical Research Service \#151-H, VA Medical Center, 1670 Clairmont Rd, 4900-0011AA, USA. ${ }^{3}$ Center for AIDS Research, Emory University School of Medicine and Veterans Affairs Medical Center, Medical Research Service \#151-H, VA Medical Center, 1670 Clairmont Rd, 4900-001-1AA, USA.

\section{Authors' contributions}

SCK conceptualized the study, contributed to the data analyses, and prepared the manuscript. CC managed the study and implemented the study protocol. DW conducted interviews and performed quality assurance for interview data. MJ conducted interviews and performed quality assurance for interview data. MOK implemented the study protocol, managed the pill count data, and contributed to the study design. MD performed laboratory analyses HIV data. AMC oversaw quality assurance and laboratory management for HIV data. RFS oversaw quality assurance and laboratory management of HIV data and contributed to the overall 
conceptualization of the study. All authors have read and approved the final manuscript.

\section{Competing interests}

The authors declare that they have no competing interests.

Received: 13 June 2011 Accepted: 10 January 2012

Published: 10 January 2012

\section{References}

1. (NCAM) NCFCaAM: What is Complimentary and Alternative Medicine. 2011 [http://nccam.nih.gov/health/atoz.htm.].

2. Mills E, Wu P, Johnston BC, Gallicano K, Clarke M, Guyatt G: Natural health product-drug interactions: a systematic review of clinical trials. Ther Drug Monit 2005, 27(5):549-57.

3. Bormann JE, Uphold CR, Maynard C: Predictors of complementary/ alternative medicine use and intensity of use among men with HIV infection from two geographic areas in the United States. J Assoc Nurses AIDS Care 2009, 20(6):468-80.

4. Hsiao AF, Wong MD, Kanouse DE, Collins RL, Liu H, Andersen RM, et al: Complementary and alternative medicine use and substitution for conventional therapy by HIV-infected patients. J Acquir Immune Defic Syndr 2003, 33(2):157-65.

5. Liu C, Yang Y, Gange SJ, Weber K, Sharp GB, Wilson TE, et al: Disclosure of complementary and alternative medicine use to health care providers among HIV-infected women. AIDS Patient Care STDs 2009, 23(11):965-71.

6. Walsh MC, Trentham-Dietz A, Schroepfer TA, Reding DJ, Campbell B, Foote $\mathrm{ML}$, et al: Cancer information sources used by patients to inform and influence treatment decisions. J Health Commun 2010, 15(4):445-63.

7. Berland GK, Elliott MN, Morales LS, Algazy Jl, Kravitz RL, Broder MS, et al: Health information on the Internet: accessibility, quality, and readability in English and Spanish. JAMA 2001, 285(20):2612-21.

8. Kalichman SC, Cain D, Cherry C, Pope H, Eaton L, Kalichman MO: Internet use among people living with HIV/AIDS: Coping and health-related correlates. AIDS Patient Care and STDs 2005, 19(7):439-48.

9. Kalichman SC, Cherry C, Cain D, Pope H, Kalichman M, Eaton L, et al: Internet-based health information consumer skills intervention for people living with HIV/AIDS. J Consult Clin Psychol 2006, 74(3):545-54.

10. Kalichman SC, Weinhardt L, Benotsch E, DiFonzo K, Luke W, Austin J: Internet access and Internet use for health information among people living with HIV-AIDS. Patient Educ Couns 2002, 46(2):109-16.

11. Ross K: Crackdown on unproven cancer treatments focuses on internet marketers. J Natl Cancer Inst 2008, 100(17):1200-2.

12. Symington A: South African court bans promotion of vitamin treatments as cures for AIDS. HIV AIDS Policy Law Rev 2008, 13(2-3):43-4.

13. Kapp C: South African court bans vitamin trials for HIV/AIDS. Lancet 2008, 372(9632):15.

14. Update: appeal in Dr Rath case lapses. HIV AIDS Policy Law Rev 2009, 14(1):50.

15. Chigwedere $P$, Essex M: AIDS denialism and public health practice. AIDS Behav 2010, 14(2):237-47.

16. Nattrass N: Still crazy after all these years: the challenge of AIDS denialism for science. AIDS Behav 2010, 14(2):248-51.

17. Grebe E, Nattrass N: AIDS Conspiracy Beliefs and Unsafe Sex in Cape Town. AIDS Behav 2011.

18. Baker DW, Parker RM, Williams MV, Clark WS: Health literacy and the risk of hospital admission. Journal of General Internal Medicine 1998, 13:791-8.

19. Kalichman SC, Rompa D, Cage M: Distinguishing between overlapping somatic symptoms of depression and HIV disease in people living with HIV-AIDS. J Nerv Ment Dis 2000, 188(10):662-70.

20. Bangsberg DR, Hecht FM, Charlebois ED, Chesney M, Moss A: Comparing objective measures of adherence to HIV antiretroviral therapy: Electronic medication monitors and unannounced pill counts. AIDS and Behavior 2001, 5:275-81.

21. Kalichman SC, Amaral CM, Cherry C, Flanagan JA, Pope H, Eaton L, et al: Monitoring Antiretroviral adherence by unannounced pill counts conducted by telephone: Reliability and criterion-related validity. HIV Clinical Trials 2008, 9:298-308.

22. Kalichman SC, Amaral CM, Stearns HL, White D, Flanagan JA, Pope H, et al: Adherence to antiretroviral therapy assessed by unannounced pill counts conducted by telephone. Journal of General Internal Medicine 2007, 22:1003-6.

23. Milan FB, Arnsten JH, Klein RS, Schoenbaum EE, Moskaleva G, Buono D, et al: Use of complementary and alternative medicine in inner-city persons with or at risk for HIV infection. AIDS Patient Care STDs 2008, 22(10):811-6.

24. Kalichman SC, Cherry C, Cain D, Weinhardt L, Benotsch E, Pope H, et al: Health Information on the Internet and People Living with HIV/AIDS: Information Evaluation and Coping Styles. Health Psychology 2006, 25:205-10.

25. Benotsch EG, Kalichman SC, Weinhardt L: HIV/AIDS patients' evaluation of health information on the Internet. Journal of Consulting and Clinical Psychology 2004, 72:1004-11.

26. Hensel M, Zoz M, Ho AD: Complementary and alternative medicine in patients with chronic lymphocytic leukemia. Support Care Cancer 2009, 17(1):47-52

27. Stone CA, Kawai K, Kupka R, Fawzi WW: Role of selenium in HIV infection. Nutr Rev 2010, 68(11):671-81.

doi:10.1186/1742-6405-9-1

Cite this article as: Kalichman et al:: Use of dietary supplements among people living with HIV/AIDS is associated with vulnerability to medical misinformation on the internet. AIDS Research and Therapy 2012 9:1.

\section{Submit your next manuscript to BioMed Central and take full advantage of:}

- Convenient online submission

- Thorough peer review

- No space constraints or color figure charges

- Immediate publication on acceptance

- Inclusion in PubMed, CAS, Scopus and Google Scholar

- Research which is freely available for redistribution 